Virginia Commonwealth University VCU Scholars Compass

2018

\title{
Central Venous Catheter Confirmation by Ultrasonography: A Novel Instructional Protocol
}

Jordan Tozer

Virginia Commonwealth University

Follow this and additional works at: https://scholarscompass.vcu.edu/med_edu

Part of the Medicine and Health Sciences Commons

(c) The Author(s)

\section{Downloaded from}

https://scholarscompass.vcu.edu/med_edu/36

This Poster is brought to you for free and open access by the School of Medicine at VCU Scholars Compass. It has been accepted for inclusion in Medical Education Symposium by an authorized administrator of VCU Scholars Compass. For more information, please contact libcompass@vcu.edu. 


\section{Jordan Tozer MD, Michael Vitto DO, Michael Joyce MD, Lindsay Taylor MD, David Evans MD}

Department of Emergency Medicine, Ultrasound Section, Virginia Commonwealth University, Richmond, VA

Purpose
$\begin{aligned} & \text { Multiple studies within last } 10 \text { years examining } \\ & \text { feasibility, speed and accuracy of ultrasound for } \\ & \text { central venous catheter malposition }\end{aligned}$
- Recent systematic review and meta-analysis from
Ablordeppey, et al:
- Ultrasound is fast (2min vs 58min)
- Ultrasound is highly sensitive and
specific for detecting catheter
malposition
- Re-demonstrates high sensitivity and
specificity for detecting
pneumothorax

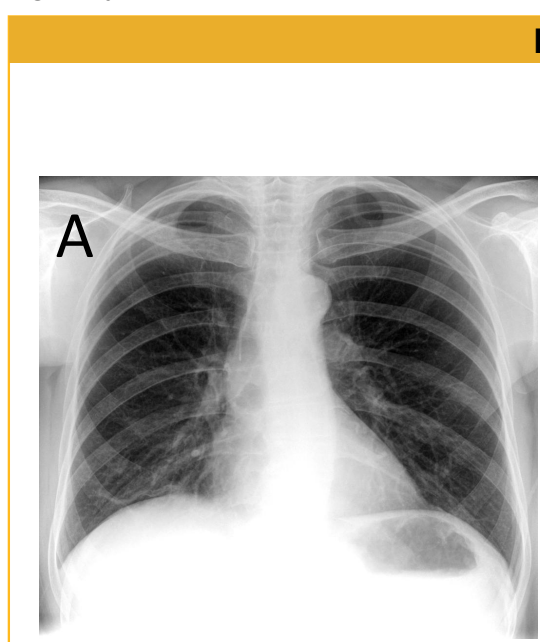

Figures
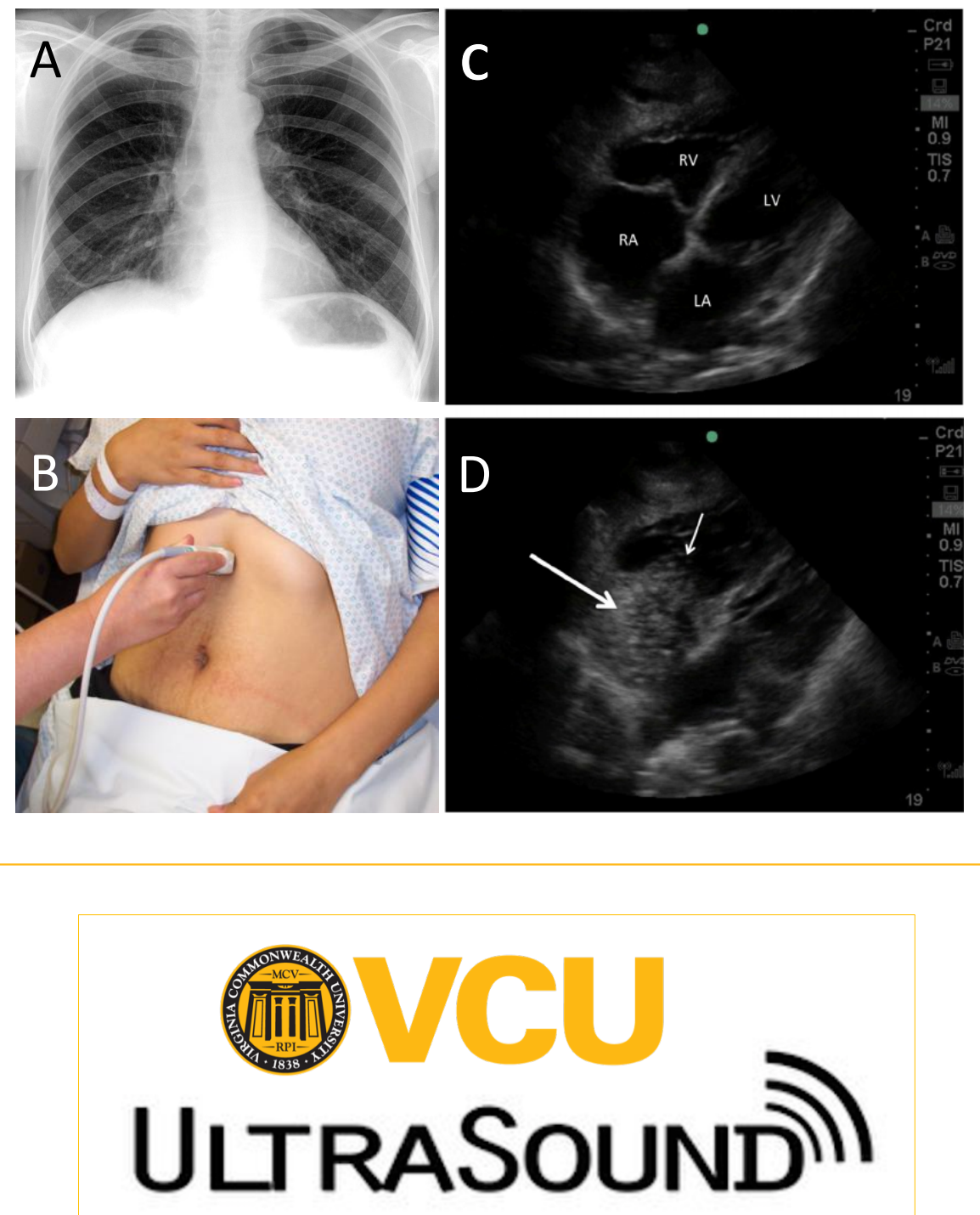

Results

- 47 EM physicians completed the online didactic session, 24 followed up to complete the simulation testing

- All 47 participants scored $94 \%$ or greater on 7 question post didactic quiz

- Demonstrates adequate

knowledge acquisition

All 24 participants scored $100 \%$ accuracy on follow up simulation scenarios 2 weeks later

- Various RASS timing

- Detection of PTX

- Demonstrates short term retention

All participants "agreed" or "strongly agreed" that the educational module improved their understanding of CVC confirmation using ultrasound and "strongly agreed" that they plan to incorporate this skill into their clinical practice

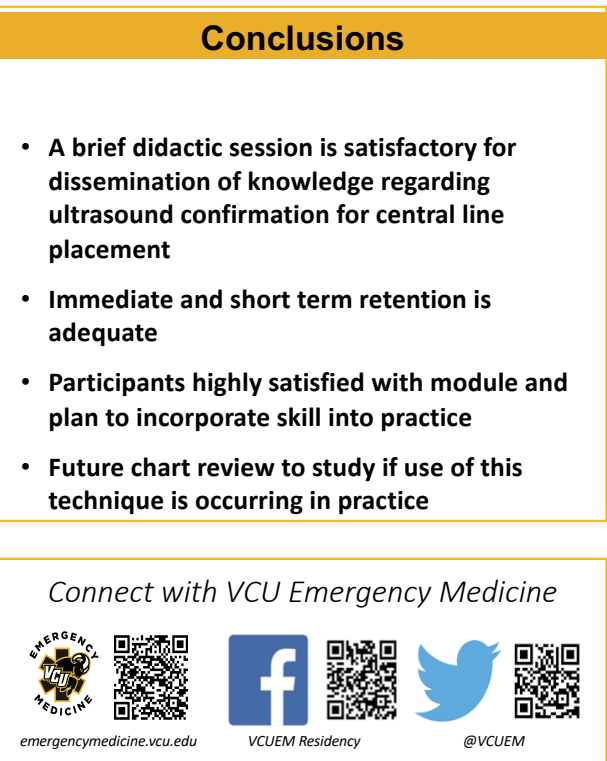

